\title{
One-step synthesis of ultra-high surface area nanoporous carbons and their application for electrochemical energy storage
}

\section{Marta Sevilla, Guillermo A. Ferrero, Noel Diez, Antonio B. Fuertes *}

Instituto Nacional del Carbón (CSIC), P.O. Box 73, Oviedo 33080, Spain

*Corresponding author: abefu@incar.csic.es

\section{Abstract}

A simple one-pot route for the synthesis of highly porous $\mathrm{N}$-doped carbons with an excellent performance as supercapacitor electrodes is presented. The synthesis scheme is based on the carbonization of an organic salt, potassium citrate, at a temperature in the $700-900{ }^{\circ} \mathrm{C}$ range, in the presence of urea. Such porous carbons combine ultra-high BET surface areas of up to $3350 \mathrm{~m}^{2} \cdot \mathrm{g}^{-1}$, a large pore volume of up to $2.65 \mathrm{~cm}^{3} \cdot \mathrm{g}^{-1}$, a porosity which can be regulated to have a micropore or micro-mesopore network and a notable nitrogen content in the $0.5-4.5 \mathrm{wt} \%$ range, two essential properties for their use in electrochemical devices. The presence of urea in the synthesis mixture is the key to pore development in these synthesized carbons. The applicability of this type of carbon as supercapacitor electrode material with an ionic liquid as electrolyte has also been demonstrated in this study. 


\section{Introduction}

Porous carbon is a versatile material that plays an important role in a large variety of emergent applications, such as the capture of $\mathrm{CO}_{2}[1,2]$, the storage of $\mathrm{H}_{2}[3,4]$ and electrochemical energy storage [3]. In particular, the design of porous carbons with well-controlled structural properties has generated renewed interest in their integration in high-performance energy storage devices (i.e., supercapacitors and Li-ion batteries) [5-8]. For these applications, unconventional carbon materials such as graphene, carbon nanotubes, carbon nanonions, etc., have already been exhaustively investigated $[9,10]$. Nevertheless, in the near future, emergent energy storage systems are expected to trigger the demand for huge amounts of highperformance porous carbons, which will need to be produced from affordable precursors by means of easy procedures. Given this situation, the development of simple synthesis strategies for producing carbons able to meet the requirements of these energy storage systems presents a real challenge. In particular, carbons with a large surface area (i.e. 2000-3000 $\mathrm{m}^{2} \cdot \mathrm{g}^{-1}$ ) and a porosity mainly made up of micropores (diameter $<2 \mathrm{~nm}$ ) and small mesopores $(<5 \mathrm{~nm})$ are in high demand for the fabrication of electrodes for use in electrochemical supercapacitors. Generally, these carbons are produced by chemical activation with $\mathrm{KOH}$ of coal/petroleum by-products (i.e. pitch) or biomass precursors $[11,12]$. However, the use of $\mathrm{KOH}$ has serious drawbacks as this compound entails numerous operational problems owing to its high corrosiveness and toxicity. Consequently, it is important to develop alternative simpler synthesis routes towards advanced porous carbons for electrochemical applications. In recent years, several alternative methods that either avoid the 
use of activating agents or that employ less corrosive activating substances have been proposed. As an example of the first case, Antonietti et al. presented a novel synthesis approach based on the fact that when a carbon precursor is thermally treated in a molten salt phase $\left(\mathrm{KCl} / \mathrm{ZnCl}{ }_{2}, \mathrm{NaCl} / \mathrm{ZnCl}_{2}, \mathrm{CaCl}_{2} \cdot 2 \mathrm{H}_{2} \mathrm{O}\right.$, $\mathrm{MgCl}_{2} \cdot 6 \mathrm{H}_{2} \mathrm{O}$, etc.), it simultaneously acts as a solvent and porogen $[13,14]$. This synthesis strategy which has been used with a variety of carbon precursors including glucose [15-18], adenine [19, 20], ionic liquids [21-23] or biomass feedstock [24] does not involve any harsh activating agent, but large amounts of salts. Zhao et al., on other hand, synthesized three-dimensional hierarchical carbons with surface areas of up to $1000 \mathrm{~m}^{2} / \mathrm{g}$ by an easy process involving the carbonization of mixtures made up of glucose as carbon precursor and nonmelting salts (i.e. $\mathrm{NaCl}, \mathrm{Na}_{2} \mathrm{CO}_{3}, \mathrm{Na}_{2} \mathrm{SiO}_{3}$ ) as template [25-27]. The use of less corrosive chemical substances as activating agents has also been analyzed by several authors. Thus, Deng et al. [28] and Sevilla and Fuertes [29] recently reported the preparation of high-surface area porous carbons from biomass products using potassium bicarbonate as activating agent. We recently showed that the chemical activation of hydrochar products with potassium oxalate and melamine gives rise to high-surface area carbons $\left(\right.$ ca. $3000 \mathrm{~m}^{2} \cdot \mathrm{g}^{-1}$ ) that match the electrochemical performance of $\mathrm{KOH}-\mathrm{ACs}$ in conventional electrolytes $\left(\mathrm{H}_{2} \mathrm{SO}_{4}\right.$ and $\left.\mathrm{TEABF}_{4} / \mathrm{AN}\right)$ and in ionic liquids [30]. Along the same lines, Schneidermann et al. [31] recently reported the preparation of $\mathrm{N}$-doped nanoporous carbons with a high surface area (of up to $3000 \mathrm{~m}^{2} \cdot \mathrm{g}^{-1}$ ) by a mechanochemical approach with lignin as carbon precursor, $\mathrm{K}_{2} \mathrm{CO}_{3}$ as activating agent and urea as nitrogen source. 
The direct carbonization of some organic salts offers an easy one-step synthesis route for obtaining highly porous carbons. These salts combine an organic moiety as carbon precursor and a metal cation as the origin of the inorganic species that act as activating agents or endo-templates. Following the same route we reported the synthesis of a variety of carbons with different pore characteristics by the carbonization of several organic salts (citrates, gluconates or alginates) of $\mathrm{K}^{+}, \mathrm{Na}^{+}, \mathrm{Ca}^{2+}, \mathrm{Fe}^{3+}$, etc. [32-34]. Such carbon materials, and in particular the carbon nanosheets obtained from potassium citrate, show an excellent performance as electrodes in supercapacitors [35]. Inspired in this synthesis strategy, herein we report a novel one-pot approach for the synthesis of $\mathrm{N}$-doped porous carbons with textural properties that match the characteristics of the best $\mathrm{KOH}$-based activated carbons, i.e. BET surface areas of up to $3350 \mathrm{~m}^{2} \cdot \mathrm{g}^{-1}$. These $\mathrm{N}$-doped carbons are prepared by means of a simple one-step thermal treatment of a mixture of potassium citrate and urea at temperatures in the $700-900{ }^{\circ} \mathrm{C}$ range. These carbon materials combine a very large BET surface area, a high porosity mainly made up of micropores, and a substantial nitrogen content in the $0.5-4.5 \mathrm{wt} \%$ range, properties essential for use in electrochemical devices. They, consequently exhibit an excellent performance as supercapacitor electrode materials in a two-electrode system with an ionic liquid as electrolyte.

\section{Experimental section}

\subsection{Synthesis of carbon materials}

In a typical synthesis procedure, $8 \mathrm{~g}$ of potassium citrate (Aldrich) and $8 \mathrm{~g}$ of urea (Aldrich) were dissolved in $60 \mathrm{~mL}$ of deionized water. The resulting solution was then frozen at $-20 \stackrel{\circ}{\circ}$. The frozen dispersion was transferred to a 
lyophilizer (Telstar Cryodos) and freeze-dried at a temperature of - $51^{\circ} \mathrm{C}$ and at a pressure of 0.06 mbar. After that, the powder was heated under $\mathrm{N}_{2}$ up to the desired temperature (i.e. $700,750,800$, or $900^{\circ} \mathrm{C}$ ) at a heating rate of $3^{\circ} \mathrm{C} / \mathrm{min}$ and held at this temperature for $2 \mathrm{~h}$ (Note: precautions should be taken when extracting the crucible from the furnace as toxic potassium cyanide is contained in the solid residue). The samples were then thoroughly washed several timeswith diluted $\mathrm{HCl}$ to remove any inorganic salts (Note: precautions should be taken when adding $\mathrm{HCl}$ as hydrogen cyanide is generated). Finally, the carbon particles were collected by filtration, washed with abundant distilled water, and dried at $120^{\circ} \mathrm{C}$ for several hours. The carbon samples were denoted as $\mathrm{CU}-\mathrm{X}$, where $\mathrm{X}$ is the reaction temperature (in ${ }^{\circ} \mathrm{C}$ ).

\subsection{Physical Characterization}

Scanning electron microscopy (SEM) images were obtained on a Quanta FEG650 (FEI) instrument, whereas transmission electron microscopy (TEM) images were recorded on a JEOL (JEM 2100-F) apparatus operating at $200 \mathrm{kV}$. The nitrogen sorption isotherms of the carbon samples were measured at 196C using a Micromeritics ASAP 2020 sorptometer. The apparent surface area was calculated by the BET method. An appropriate relative pressure range was selected to ensure that a positive line intersect of multipoint BET fitting $(C>$ 0 ) would be obtained and $V_{\text {ads }}\left(1-P / P_{0}\right)$ would increase with $P / P_{0}$ [36]. The total pore volume was determined from the amount of nitrogen adsorbed at a relative pressure (P/P0) of 0.95 . The pore size distributions (PSD) were determined by means of the Quench Solid State Density Functional Theory (QSDFT) method for nitrogen. X-ray diffraction (XRD) patterns were obtained on a Siemens D5000 instrument operating at $40 \mathrm{kV}$ and $20 \mathrm{~mA}$, using a $\mathrm{Cu} \mathrm{KR}$ radiation 
source. The Raman spectra were recorded on a Horiva (LabRam HR-800) spectrometer. The source of radiation was a laser operating at a wavelength of $514 \mathrm{~nm}$ and at a power of $25 \mathrm{~mW}$. X-ray photoelectron spectroscopy (XPS) was carried out on a Specs spectrometer, using Mg KR (1253.6 eV) radiation from a double anode at $150 \mathrm{~W}$. The elemental analysis of the samples was carried out on a LECO CHN-932 microanalyzer.

\subsection{Electrochemical Characterization.}

The electrodes were prepared by mixing 85 wt \% of active material with 10 wt \% of polytetrafluoroethylene (PTFE) binder (Aldrich, 60 wt \% suspension in water) and 5\% Super C65 (Timcal). The electrochemical measurements were performed in a two-electrode Swagelok ${ }^{\mathrm{TM}}$ type cells using pure EMIMTFSI (1Ethyl-3-methylimidazolium bis(trifluoromethylsulfonyl)imide) (99\%, Ionic Liquids Technology, Germany) electrolyte solutions and stainless steel current collectors. In the case of $\mathrm{CU}-800$, mass balancing was performed to increase stability at $3 \mathrm{~V}$ (mass positive electrode $=1.1 \times$ mass negative electrode), whereas for CK-800, electrodes of the same mass were used. In both cases, the electrode porous carbon load was close to commercial values, i.e. an average mass loading of $7 \mathrm{mg} \mathrm{cm}^{-2}$. The electrochemical characterization was performed at room temperature using a computer-controlled potentiostat (Biologic VMP3 multichannel generator) and consisted of cyclic voltammetry experiments (CV), and galvanostatic charge/discharge (CD) cycling tests.

Cyclic voltammetry experiments were conducted between 0 and $3 \mathrm{~V}$, at increasing sweep rates from $1 \mathrm{mV} \mathrm{s}^{-1}$ to $80 \mathrm{mV} \mathrm{s}^{-1}$. Plots of cell specific capacitance vs. voltage were calculated using the formula: 


$$
\mathrm{C}_{\text {cell }}=\frac{\mathrm{I}}{v \cdot \mathrm{m}}
$$

where $\mathrm{I}=$ current $(\mathrm{A}), \mathrm{v}=$ scan rate $\left(\mathrm{V} \mathrm{s}^{-1}\right)$ and $\mathrm{m}=$ mass (grams) of porous carbon material in the supercapacitor.

Galvanostatic charge/discharge cycling was carried out in the same voltage range, at increasing current densities from 0.1 to $15 \mathrm{~A} \mathrm{~g}^{-1}$, based on the average active mass per electrode. The specific gravimetric capacitance of the supercapacitor was determined from the galvanostatic cycles by means of the formula:

$$
C_{\text {cell }}=\frac{I}{(d V / d t) \cdot m}
$$

where $\mathrm{dV} / \mathrm{dt}=$ the slope of the discharge curve $\left(\mathrm{V} \mathrm{s}^{-1}\right)$. As most supercapacitors are operated in the range of $V_{\max }$ to approximately $1 / 2 V_{\max }$, the upper half of the discharge curve was used to determine the slope of the discharge curve [37].

To trace the Ragone plots, the specific energy $\left(\mathrm{Wh} \mathrm{kg}^{-1}\right)$ and power ( $\mathrm{kW}$ $\mathrm{kg}^{-1}$ ) were calculated using the following formulae:

$$
\begin{aligned}
& E=\frac{1}{2} C_{\text {cell }} \Delta V_{d}{ }^{2} \\
& P=\frac{E}{\Delta t_{d}}
\end{aligned}
$$

where $\Delta V_{d}$ is the operation voltage $\left(V_{\max }-I R_{d r o p}\right)$ and $\Delta_{t d}$ is the discharge time. Long-term cycling stability was evaluated by continuous galvanostatic charge/discharge cycling over 10000 cycles at $5 \mathrm{~A} \mathrm{~g}^{-1}$ and at the maximum cell voltage, i.e. $3 \mathrm{~V}$.

\section{Results and discussion}

3.1. Structural and chemical properties of the porous carbons 
As illustrated in Scheme 1, the direct carbonization of potassium citrate leads to the formation of carbon particles consisting of interconnected nanosheets with a well-developed porosity [35]. A precise picture of the
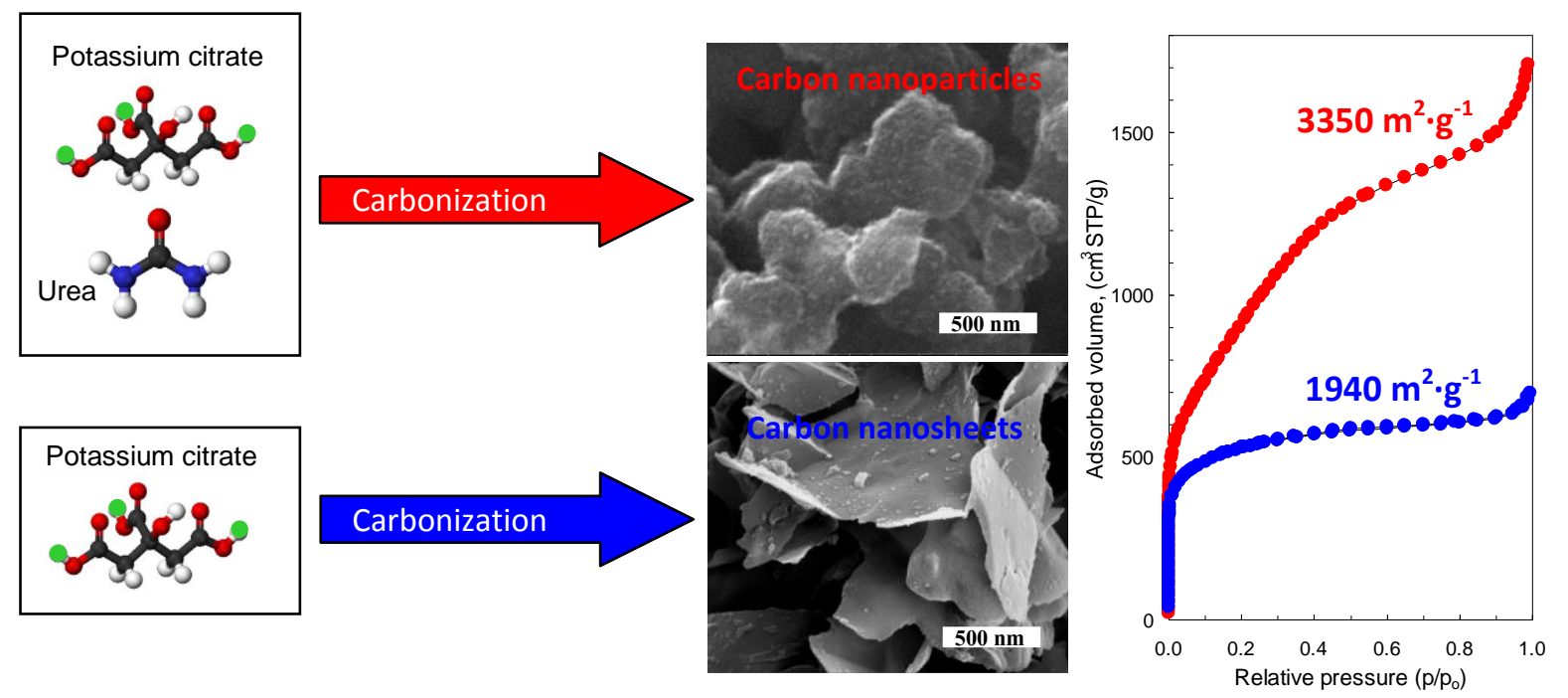

Scheme 1. Illustration of the synthesis and characteristics of the porous carbon obtained using potassium citrate and a potassium citrate/urea mixture.

morphology of this type of carbon particles is provided by the SEM images in Figure S1. In contrast, when the potassium citrate is carbonized in the presence of urea, the structural characteristics of the generated porous carbon are completely different, as is shown in Scheme 1. Instead of interconnected carbon nanosheets, the carbonization of potassium citrate/urea mixtures gives rise to irregular particles that have a conchoidal appearance, which indicates that the reactive mixture has melted during carbonization (Figures 1a and 1b). As can be seen in the SEM images in Figures 1c and 1d, the particles are made up of an agglomeration of carbon nanoparticles (particle size $\sim 100 \mathrm{~nm}$ ) surrounded by a thin carbon layer. The microstructure of the carbon particles was further examined by means of transmission electron microscopy (TEM). The HRTEM microphotographs shown in Figures $1 \mathrm{e}$ and 1f, which were taken at the edge of a carbon particle, reveal that the porosity is made up of randomly oriented 
narrow micropores, anticipating the results to be obtained from the nitrogen physisorption measurements (vide infra).
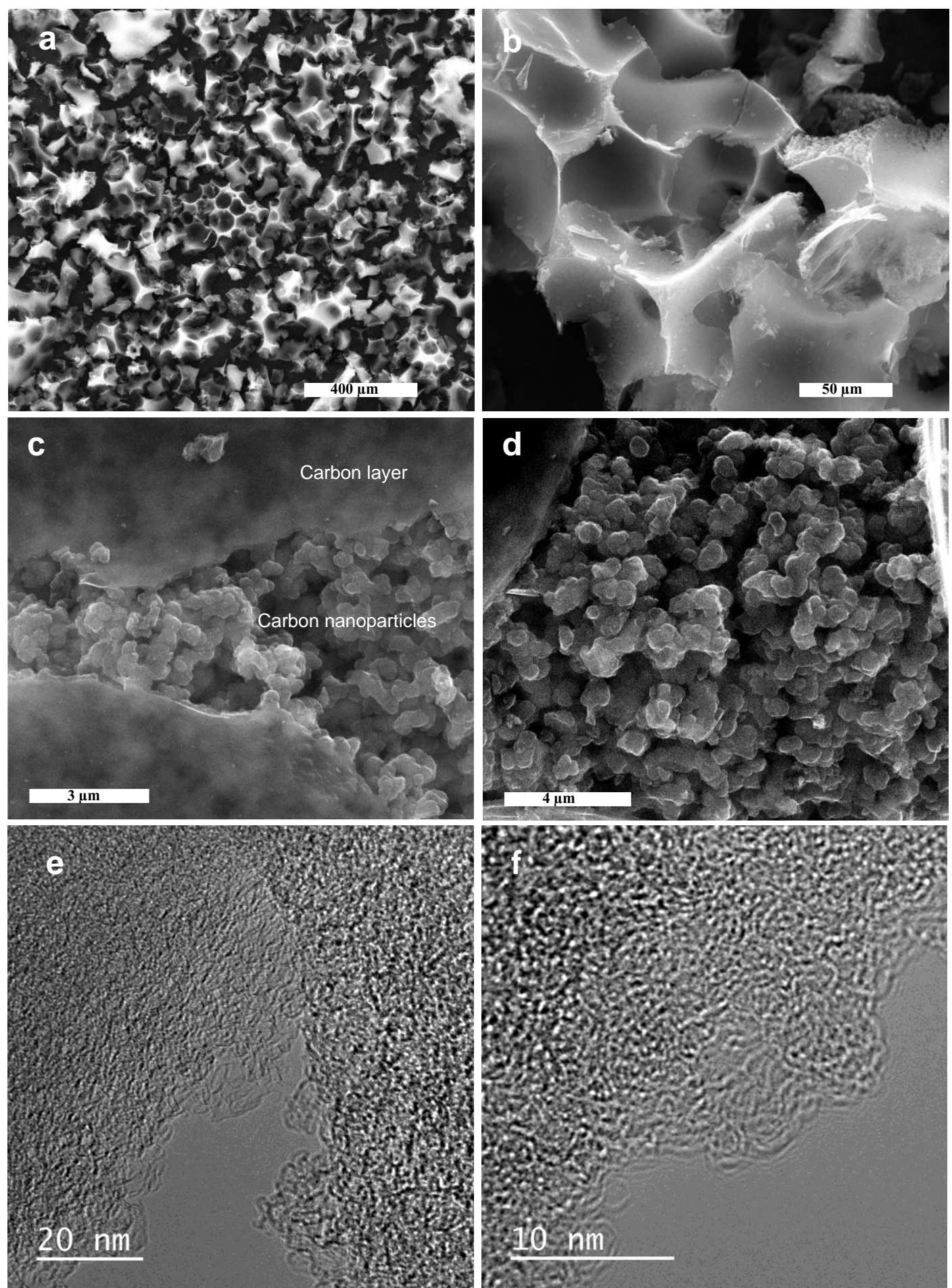

Figure 1. (a-d) SEM and (e, f) HRTEM images obtained from the CU-800 sample. 
The nitrogen sorption isotherms and corresponding pore size distributions (PSDs) of the porous carbons prepared at temperatures between 700 and $900{ }^{\circ} \mathrm{C}$ are displayed in Figures $2 \mathrm{a}$ and $2 \mathrm{~b}$ respectively. Variations in the shape of the isotherms as the temperature rises from $700{ }^{\circ} \mathrm{C}$ to $750-900{ }^{\circ} \mathrm{C}$ indicate changes in the porous structure of the activated carbon, in particular a widening of the pores. Indeed, the PSDs in Figure $2 \mathrm{~b}$ indicate that the porosity of the sample obtained at $700{ }^{\circ} \mathrm{C}$ is made up mostly of narrow micropores $(70 \%$ of pore volume) with a bimodal distribution with sizes centered at $0.85 \mathrm{~nm}$ and 1.5 $\mathrm{nm}$. On the other hand, the carbon samples obtained at higher temperatures (i.e. 750-900 ${ }^{\circ} \mathrm{C}$ ) also exhibit two pore systems, one of which is made up of narrow micropores with sizes centered at around $0.85 \mathrm{~nm}$, as in the CU-700 sample. However, in these samples, unlike CU-700, and independently of the carbonization temperature, the porosity corresponding to the second pore system is made up of supermicropores (1.5-2 nm) and small mesopores (up to $5 \mathrm{~nm}$ ) (see Figure 2b). The textural parameters of these carbon materials are listed in Table 1. It can be seen that they exhibit exceptionally large BET surface areas and pore volumes with values in the $2750-3350 \mathrm{~m}^{2} \cdot \mathrm{g}^{-1}$ and $1.56-$ $2.65 \mathrm{~cm}^{3} \cdot \mathrm{g}^{-1}$ ranges, respectively. A large fraction of the pore volume corresponds to micropores $(<2 \mathrm{~nm})$, around $70 \%$ in the case of the CU-700 sample (see Table 1). Worth noting is that the carbon samples obtained in the 750-900 ${ }^{\circ} \mathrm{C}$ range have outstanding textural properties, which are superior to those of most of the activated carbons obtained by chemical activation with $\mathrm{KOH}$. For example, the carbon obtained at $800 \stackrel{\circ}{\mathrm{C}}$ has a BET surface area of $3350 \mathrm{~m}^{2} \cdot \mathrm{g}^{-1}$ and a pore volume of $2.65 \mathrm{~cm}^{3} \cdot \mathrm{g}^{-1}$. This result deserves highlighting 
given the simplicity of the synthesis procedure and the harmless nature of the chemical precursors used (i.e. potassium citrate and urea).
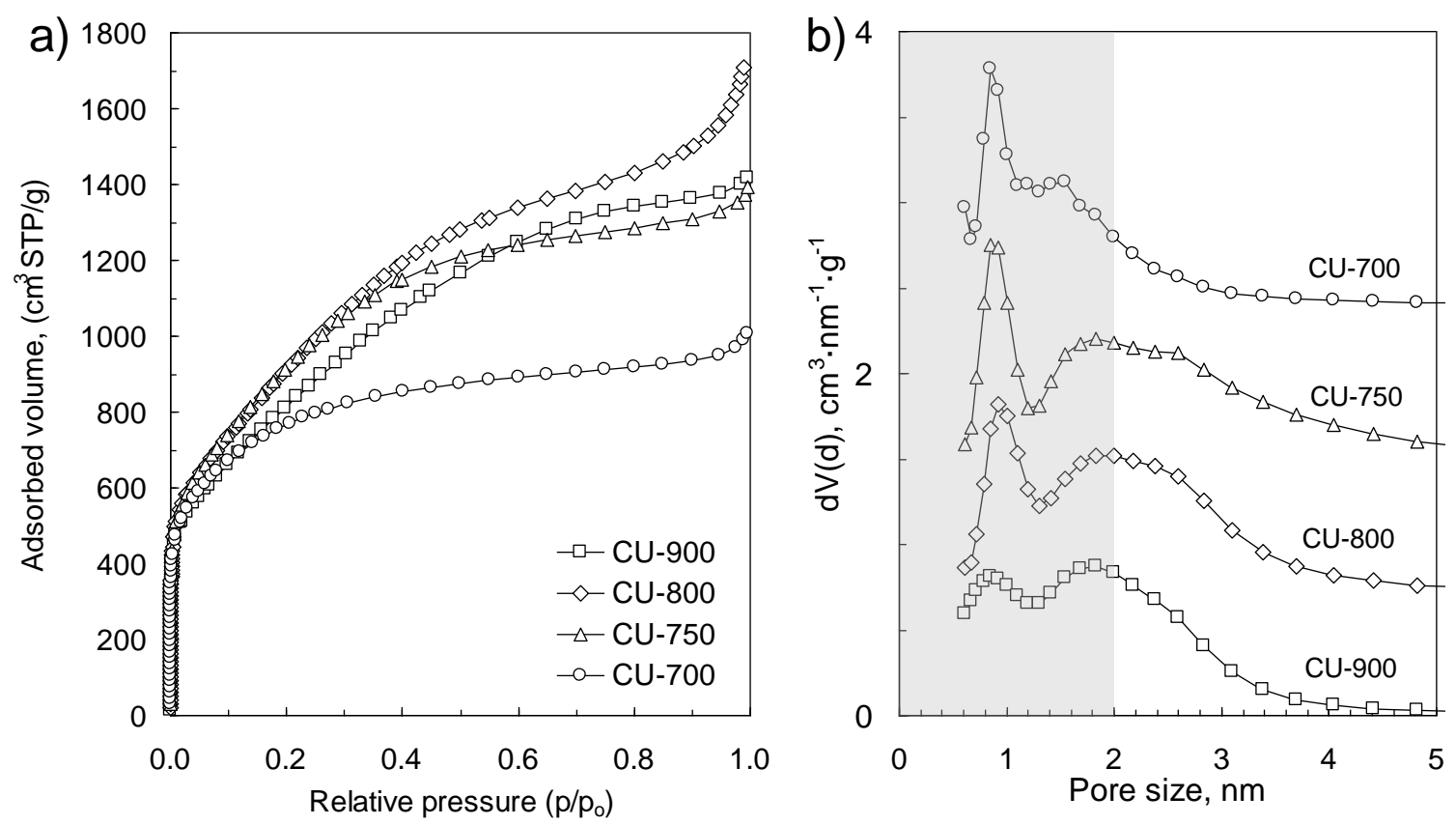

Figure 2. a) Nitrogen sorption isotherms and b) pore size distributions of the porous carbons obtained from the potassium citrate/urea mixtures at different temperatures. The shaded area in b) indicates the micropore range.

Table 1. Textural and chemical properties of the porous carbon samples.

\begin{tabular}{llllllll}
\hline Sample & $\mathrm{S}_{\mathrm{BET}}$ & $\mathrm{V}_{\mathrm{p}}$ & $\mathrm{V}_{\text {micro }}$ & $\mathrm{V}_{\text {meso }}$ & \multicolumn{2}{l}{ Chemical composition (wt \%) } \\
\cline { 7 - 9 } & $\left(\mathrm{m}^{2} \cdot \mathrm{g}^{-1}\right)$ & $\left(\mathrm{cm}^{3} \cdot \mathrm{g}^{-1}\right)$ & $\left(\mathrm{cm}^{3} \cdot \mathrm{g}^{-1}\right)^{\mathrm{a}}$ & $\left(\mathrm{cm}^{3} \cdot \mathrm{g}^{-1}\right)$ & $\mathrm{C}$ & $\mathrm{N}$ & $(\mathrm{C} / \mathrm{N})_{\text {at }}$ \\
\hline $\mathrm{CU}-700$ & 2750 & 1.56 & $1.08(70)$ & 0.48 & 76.0 & 4.53 & 19.6 \\
$\mathrm{CU}-750$ & 3350 & 2.16 & $1.16(54)$ & 1.0 & 86.2 & 3.27 & 30.8 \\
$\mathrm{CU}-800$ & 3350 & 2.65 & $1.07(40)$ & 1.58 & 84.5 & 2.68 & 36.9 \\
CU-900 & 2970 & 2.19 & $0.93(42)$ & 1.26 & 90.3 & 0.46 & 230 \\
CK-800 & 1940 & 0.96 & $0.77(80)$ & 0.19 & 76.8 & nil & -
\end{tabular}

${ }^{\mathrm{a}}$ The percentage of pore volume corresponding to the micropores is given in parentheses

In order to assess the contribution of urea to the development of porosity, we compared the textural characteristics of the CU-800 carbon obtained from the potassium citrate/urea mixture and the sample prepared by direct 
carbonization of potassium citrate at $800{ }^{\circ} \mathrm{C}(\mathrm{CK}-800)$. The results in Table 1 reveal that the BET surface area and the pore volume of the carbon synthesized in the presence of urea (CU-800) are considerably larger (3350 $\mathrm{m}^{2} \cdot \mathrm{g}^{-1}$ and $V_{p}=2.65 \mathrm{~cm}^{3} \cdot \mathrm{g}^{-1}$ ) than the values obtained for the CK-800 carbon produced from just potassium citrate $\left(1940 \mathrm{~m}^{2} \cdot \mathrm{g}^{-1}\right.$ and $\left.V_{p}=0.96 \mathrm{~cm}^{3} \cdot \mathrm{g}^{-1}\right)$. The nitrogen sorption isotherms, PSDs and the change in cumulative pore volume with pore size are represented in Figure 3 for both samples. A comparison of the PSDs shows that, whereas the porosity of the CK-800 carbon is made up almost exclusively of micropores, the CU-800 carbon shows an enlargement of the pore sizes, and its porosity is made up by two pore systems centred at 0.9 $\mathrm{nm}$ and $2 \mathrm{~nm}$. However, in spite of this widening of porosity, the CU-800 sample has a high micropore volume, which is greater than that of CK-800, as can be deduced from Figure 3c. These results clearly evidence that the presence of urea in the reaction mixture is crucial to achieving porous carbon materials with outstanding textural properties.
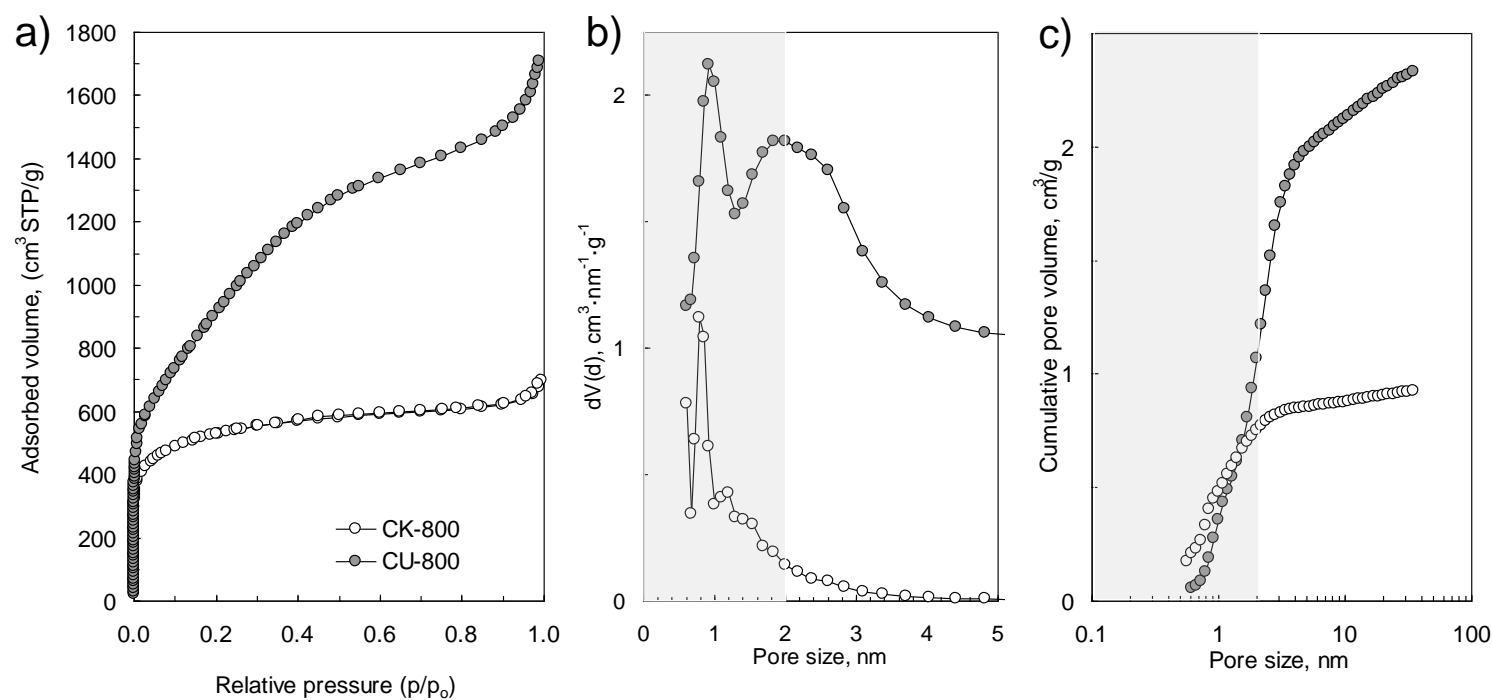

Figure 3. Comparison of the textural properties of the porous carbons obtained from the potassium citrate (CK-800) and potassium citrate/urea mixtures (CU800 ) at $800^{\circ} \mathrm{C}$. a) Nitrogen adsorption isotherms, b) pore size distributions and c) 
modification of the cumulative pore volume with pore size. The shaded areas in b) and c) indicate the micropore range.

The structural order of the porous carbon samples was investigated by means of X-ray diffraction (XRD) and Raman spectroscopy. The XRD patterns displayed in Figure S2a do not show any traces of inorganic compounds, which proves that they were completely removed by acid washing. In contrast, they exhibit a weak broad band at $2 \theta \sim 25-26^{\circ}$, which is characteristic of highly porous carbons with a disordered framework. This disordered structure is corroborated by the Raman spectra in Figure S2b. The D band at $\sim 1350 \mathrm{~cm}^{-1}$ associated with a double-resonance Raman process in disordered carbon is quite intense and broad, and overlaps a similarly broad $\mathrm{G}$ band (at $1580 \mathrm{~cm}^{-1}$ ), which is ascribed to bond stretching of all the pairs of $\mathrm{sp}^{2}$ atoms in both the rings and the chains $[38,39]$. The ratio of integrated intensities, $I_{D} / I_{G}$, which is used to measure the degree of disorder in carbon materials, has a value in the 1.9-2.2 range, which is typical of disordered carbons.

The presence of urea in the synthesis mixture not only contributes to improving the textural properties, but also causes nitrogen groups to be incorporated into the carbon framework. This is because, a fraction of the urea decomposes as the temperature increases, generating $\mathrm{NH}_{3}$ that may act as a nitrogen doping agent. Furthermore, at temperatures of $\sim 500^{\circ} \mathrm{C}$, the remaining urea may condense into $g-\mathrm{C}_{3} \mathrm{~N}_{4}$, which rapidly decomposes at higher temperatures into active $\mathrm{N}$-species $\left(\mathrm{C}_{\mathrm{x}} \mathrm{N}_{\mathrm{y}}{ }^{*}\right)$ that react with the carbonaceous matter, causing the incorporation of nitrogen heteroatoms into the carbon framework [40]. The chemical composition $(\mathrm{C}, \mathrm{N})$ of the carbon materials was determined by elemental analysis, the results of which are listed in Table 1. As 
can be seen, the samples obtained at 700,750 and $800{ }^{\circ} \mathrm{C}$ have remarkable nitrogen contents of $4.53 \mathrm{wt} \%, 3.27 \mathrm{wt} \%$ and $2.68 \mathrm{wt} \%$ respectively. However, at $900{ }^{\circ} \mathrm{C}$ the nitrogen content drops down to only $0.46 \mathrm{wt} \%$, which is indicative of the instability of the $\mathrm{N}$-groups at high temperatures. The analysis of the chemical nature of the nitrogen functional groups was performed by means of X-ray photoelectron spectroscopy (XPS). The high-resolution N 1s spectra, displayed in Figure S3, can be deconvoluted in three main peaks that can be assigned to pyridinic-N $(398.7 \pm 0.2 \mathrm{eV})$, pyrrolic-/pyridonic-N $(400.1 \pm 0.1 \mathrm{eV})$ and quaternary- $\mathrm{N}(401.3 \pm 0.3 \mathrm{eV})[41,42]$. A clear decrease in the number of less stable species, i.e. pyrrolic-/pyridonic- $\mathrm{N}$, and an increase of the more stable ones, i.e. pyridinic- and quaternary- $\mathrm{N}$, is observable as the carbonization temperature increases (see Table S1).

\subsection{Mechanistic aspects of the activation process}

In previous works we observed that when a carbon precursor is activated with a variety of chemical agents (i.e. $\mathrm{KOH}$, potassium oxalate, potassium carbonate or potassium bicarbonate) in the presence of certain nitrogen compounds (i.e. melamine or urea) or when a carbon precursor has a high nitrogen content (i.e. polypyrrole), the resulting porous carbons always exhibit an outstanding pore development with BET surface areas $>3000 \mathrm{~m}^{2} \cdot \mathrm{g}^{-1}$ and a bimodal porosity made up of micropores and small mesopores [29, 43-47]. Similar results have recently been reported by other authors $[31,48,49]$. These exceptional textural characteristics are significantly superior to those obtained by chemical activation in the absence of nitrogen compounds. However, it is important to note that the action of nitrogen compounds (i.e. urea, melamine, 
etc.) on their own is not enough to generate porosity. The above findings are in agreement with the results of the present study.

It is generally agreed that the porosity generated during chemical activation is mainly due to redox reactions between the carbonaceous material and certain oxoanions associated with the activating agent (i.e. $\mathrm{OH}^{-}, \mathrm{CO}_{3}{ }^{=}$, $\mathrm{SO}_{4}{ }^{\prime}$, etc.) [16]. This is the case of the self-activation of potassium citrate, which quickly decomposes into potassium carbonate and a melted carbonaceous phase. Potassium carbonate appears at around $300^{\circ} \mathrm{C}$, as can be seen from the XRD patterns (see Figure 4a). At higher temperatures, the partial oxidation of the carbonaceous matter by $\mathrm{K}_{2} \mathrm{CO}_{3}$ takes place according to the following redox reaction $[50,51]$ :

$$
\mathrm{K}_{2} \mathrm{CO}_{3}+2 \mathrm{C} \rightarrow 2 \mathrm{~K}+3 \mathrm{CO}
$$

This reaction is the main cause of the formation of a large number of pores within the carbon matrix. A considerable fraction of the $\mathrm{K}_{2} \mathrm{CO}_{3}$ remains unchanged because it is not involved in the redox reaction and, in consequence, the carbonized solid contains numerous $\mathrm{K}_{2} \mathrm{CO}_{3}$ nanoparticles mixed with the carbon, as can be inferred from the XRD pattern in Figure 4a.

When potassium citrate is heat-treated together with urea, instead of potassium carbonate, potassium cyanate $(\mathrm{KCNO})$ is formed at relatively low temperatures ( $150^{\circ} \mathrm{C}$, see Figure $\left.4 \mathrm{~b}\right)$. This compound is produced by the reaction between urea and potassium carbonate:

$2 \mathrm{OC}\left(\mathrm{NH}_{2}\right)_{2}+\mathrm{K}_{2} \mathrm{CO}_{3} \rightarrow 2 \mathrm{KOCN}+2 \mathrm{NH}_{3}+\mathrm{H}_{2} \mathrm{O}+\mathrm{CO}_{2}$

This fact clearly suggests that, even at this low temperature, potassium citrate is decomposed in a certain extent and nascent potassium carbonate is therefore 
generated. At around $300{ }^{\circ} \mathrm{C}, \mathrm{KCNO}$ melts together with the carbonaceous matter. The XRD patterns in Figure $4 \mathrm{~b}$ reveal that up to $500{ }^{\circ} \mathrm{C}$ potassium cyanate is the main inorganic phase. However, at higher temperatures (i.e. 650 ${ }^{\circ} \mathrm{C}$ ), potassium cyanide appears, and at $800{ }^{\circ} \mathrm{C}$ it is the principal inorganic phase with only minor traces of potassium cyanate (see Figure $4 b$ ). This result suggests that potassium cyanate is reduced to potassium cyanide by the carbon according to the following reaction:

$\mathrm{KCNO}+\mathrm{C} \rightarrow \mathrm{KCN}+\mathrm{CO}$

It seems reasonable to assume, therefore, that the outstanding pore development of carbons produced in the presence of urea is mainly due to the oxidation of carbon by potassium cyanate. 

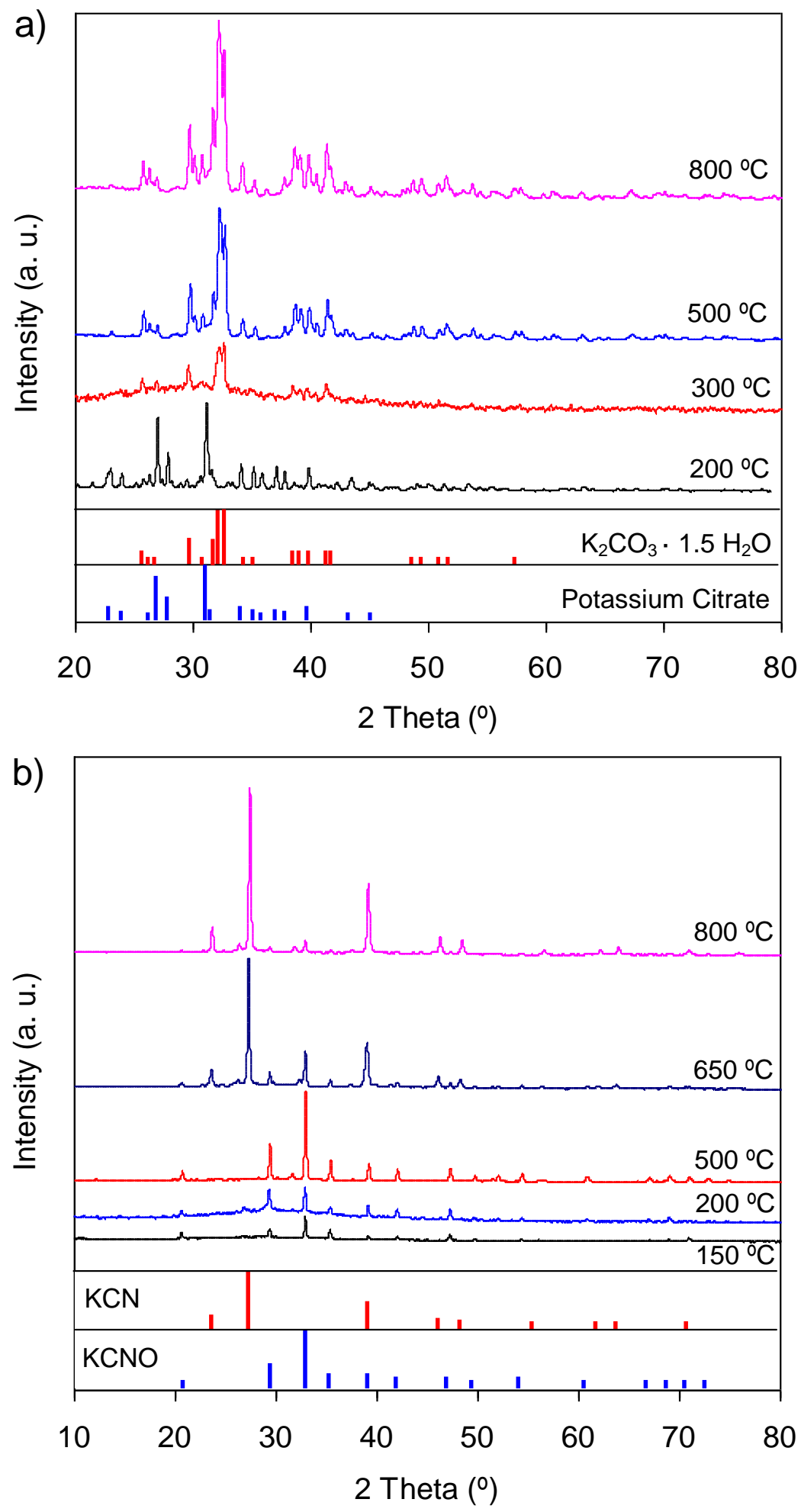

Figure 4. XRD patterns of (a) potassium citrate and (b) potassium citrate/urea mixture at different carbonization temperatures. 
3.3. Application of the porous carbons as supercapacitors with ionic liquid as electrolyte

The materials derived from potassium citrate/urea mixtures heat-treated at temperatures $\geq 750{ }^{\circ} \mathrm{C}$ have high surface areas arising from the large proportion of micropores that favour an enhanced ion adsorption capacity and small mesopores that favour enhanced ion transport kinetics. The combination of these properties make these carbons very appealing as supercapacitor electrodes with ionic liquid as electrolyte. As proof-of-concept, CU-800 was used to assemble a supercapacitor with pure EMIMTFSI, using a carbon loading close to commercial values, i.e. $7 \mathrm{mg} \mathrm{cm}^{-2}$ (electrode thickness $\sim 300$ $\mu \mathrm{m})$. As can be seen from the almost square-shaped voltammograms in Figure $5 a$, the charge propagation is very good even at rates as high as $50 \mathrm{mV} \mathrm{s}^{-1}$, despite the thick electrodes, which shows the effective role that the mesopores play in facilitating the diffusion of ions in poorly conductive and viscous electrolytes. Cell capacitance and rate capability were evaluated more precisely by galvanostatic charge/discharge cycling, the results of which are shown in Figure $5 b$, together with those of the exclusively microporous carbon nanosheets CK-800. As can be seen, the CU-800-based supercapacitor exhibits both a higher specific capacitance and rate capability than the CK-800based supercapacitor. For example, at a high rate of $10 \mathrm{~A} \mathrm{~g}^{-1}$, the CU-800based supercapacitor has a specific capacitance of $33 \mathrm{~F} \mathrm{~g}^{-1}$ vs. $22 \mathrm{~F} \mathrm{~g}^{-1}$ for the CK-800-based supercapacitor, with a rate capability of $75 \%$ vs. only $58 \%$ for the CK-800-based supercapacitor. This translates into an enhancement of $20 \%$ in the amount of energy stored at low power and an increase of up to $100 \%$ at high power (e.g. $30 \mathrm{Wh} \mathrm{kg}^{-1}$ for the CU-800-based supercapacitor vs. $15 \mathrm{Wh} \mathrm{kg}^{-}$ 
${ }^{1}$ at $6.4 \mathrm{~kW} \mathrm{~kg}^{-1}$ for the CK-800-based supercapacitor) as can be seen in Figure 5c. As for long-term cycling stability, both materials exhibit a similar capacitance retention of $\sim 90 \%$ after 10000 cycles at $5 \mathrm{~A} \mathrm{~g}^{-1}$ (Figure $5 \mathrm{~d}$ ).
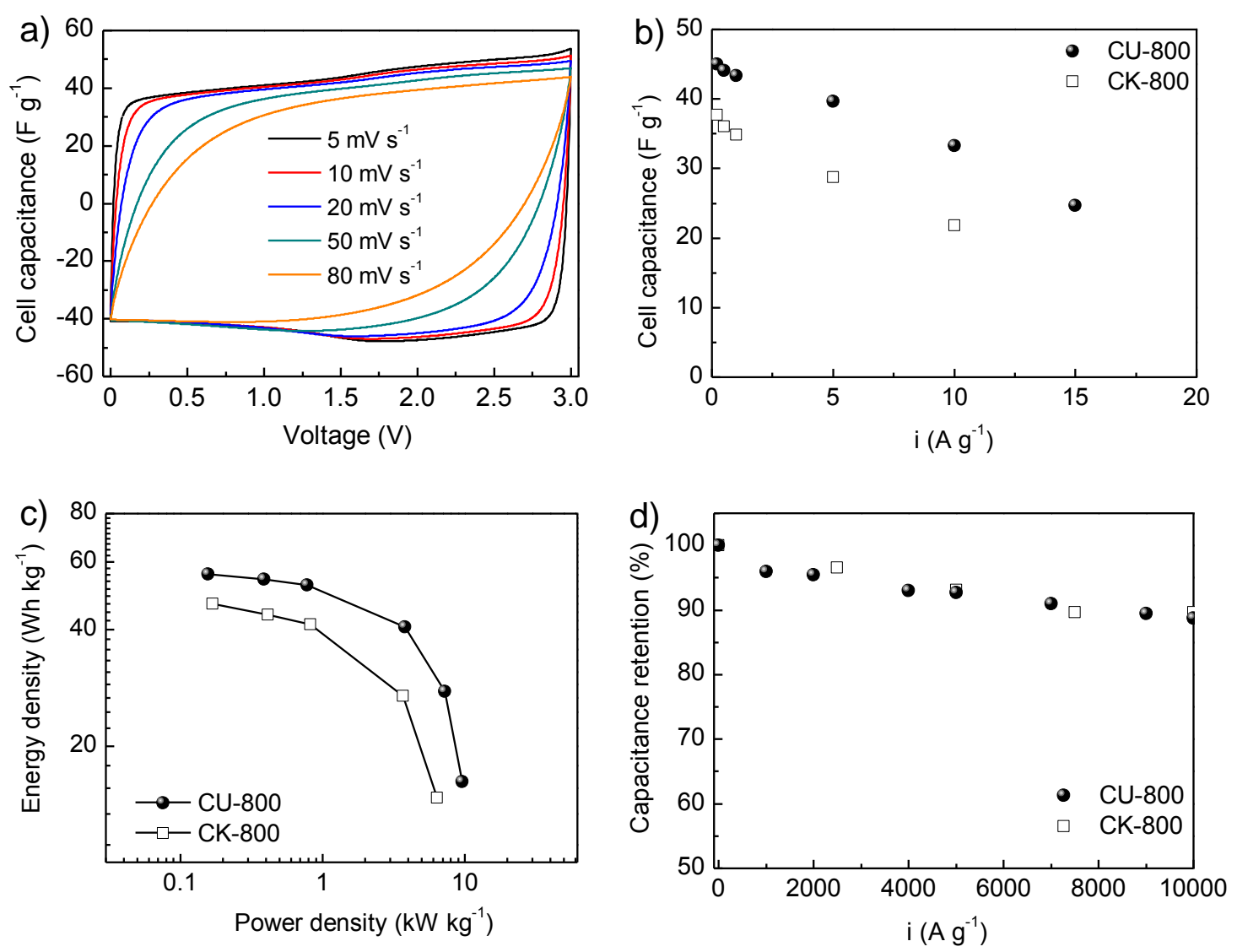

Figure 5. (a) Cyclic voltammograms recorded at different scan rates for the CU800-based supercapacitor, and (b) the rate capability as evaluated by galvanostatic charge/discharge cycling, (c) Ragone-like plots and (d) the longterm cycling stability of the supercapacitors assembled with CK-800 and CU800. 


\section{Conclusions}

In summary, we have reported a novel and simple one-pot approach for producing porous carbons with an exceptional pore development. These carbon materials are easily produced by the carbonization of potassium citrate in the presence of urea at temperatures in the $700-900{ }^{\circ} \mathrm{C}$ range. In this way, the pyrolysis of the organic moiety (i.e. citrate) and the generation of porosity can be integrated in only one step. Such porous carbons combine ultra-high BET surface areas of up to $3350 \mathrm{~m}^{2} \cdot \mathrm{g}^{-1}$, a large pore volume of up to $2.65 \mathrm{~cm}^{3} \cdot \mathrm{g}^{-1}$, a porosity which can be regulated between micropore and micro-mesopore networks and a notable nitrogen content in the $0.5-4.5 \mathrm{wt} \%$ range. The addition of urea to the synthesis mixture is the key factor for achieving these exceptional textural properties. Under these circumstances, the generation of porosity takes place via the oxidation of carbon by potassium thiocyanate instead of potassium carbonate, as occurs in the carbonization of potassium citrate. It can be assumed therefore that the generation of potassium thiocyanate is the factor responsible for this extraordinary pore development. The supercapacitor assembled using this type of carbon, mass loadings close to commercial values and a pure ionic liquid at room temperature as electrolyte exhibits a specific capacitance of $44 \mathrm{~F} \mathrm{~g}^{-1}$ at low rates and $25 \mathrm{~F} \mathrm{~g}^{-1}$ at a high rate of $15 \mathrm{~A} \mathrm{~g}^{-1}$. It is able to store up to $56 \mathrm{~W} \mathrm{~h} \mathrm{~kg}^{-1}$, and still $16 \mathrm{~W} \mathrm{~h} \mathrm{~kg}^{-1}$ at ca. $10 \mathrm{~kW} \mathrm{~kg}^{-1}$.

\section{Acknowledgments}

This research work was supported by the FICYT Regional Project (GRUPIN14102), and the Spanish MINECO-FEDER (CTQ2015-63552-R). 


\section{References}

[1] Patel HA, Byun J, Yavuz CT. Carbon Dioxide Capture Adsorbents: Chemistry and Methods. ChemSusChem 2017;10(7):1303-17.

[2] Creamer AE, Gao B. Carbon-Based Adsorbents for Postcombustion CO2 Capture: A Critical Review. Environ Sci Technol 2016;50(14):7276-89.

[3] Sevilla M, Mokaya R. Energy storage applications of activated carbons: supercapacitors and hydrogen storage. Energy Environ Sci 2014;7(4):1250-80.

[4] Yu X, Tang Z, Sun D, Ouyang L, Zhu M. Recent advances and remaining challenges of nanostructured materials for hydrogen storage applications. Progress in Materials Science 2017;88(Supplement C):1-48.

[5] Béguin F, Presser V, Balducci A, Frackowiak E. Carbons and Electrolytes for Advanced Supercapacitors. Adv Mater 2014;26(14):2219-51.

[6] Deng Y, Xie Y, Zou K, Ji X. Review on recent advances in nitrogen-doped carbons: preparations and applications in supercapacitors. J Mater Chem A 2016;4(4):1144-73.

[7] Wang H, Li Z, Mitlin D. Tailoring Biomass-Derived Carbon Nanoarchitectures for High-Performance Supercapacitors. ChemElectroChem 2014;1(2):332-7.

[8] Wang J, Nie P, Ding B, Dong S, Hao X, Dou H, et al. Biomass derived carbon for energy storage devices. J Mater Chem A 2017;5(6):2411-28.

[9] Wen L, Li F, Cheng H-M. Carbon Nanotubes and Graphene for Flexible Electrochemical Energy Storage: from Materials to Devices. Adv Mater 2016;28(22):4306-37.

[10] Zeiger M, Jackel N, Mochalin VN, Presser V. Review: carbon onions for electrochemical energy storage. J Mater Chem A 2016;4(9):3172-96.

[11] Wang J, Kaskel S. KOH activation of carbon-based materials for energy storage. J Mater Chem 2012;22(45):23710-25.

[12] Linares-Solano A, Lozano-Castell $\sqrt{ } \geq \mathrm{D}$, Lillo-R $\sqrt{ } \geq$ denas MA, Cazorla-Amor $\sqrt{ } \geq \mathrm{s}$ D. Carbon Activation by Alkaline Hydroxides. Chemistry \& Physics of Carbon: CRC Press 2007, p. 1-62.

[13] Liu X, Fechler N, Antonietti M. Salt melt synthesis of ceramics, semiconductors and carbon nanostructures. Chem Soc Rev 2013;42(21):8237-65.

[14] Fellinger T-P. Sol-gel carbons from ionothermal syntheses. J Sol-Gel Sci Technol 2017;81(1):52-8.

[15] Liu X, Antonietti M. Moderating Black Powder Chemistry for the Synthesis of Doped and Highly Porous Graphene Nanoplatelets and Their Use in Electrocatalysis. Adv Mater 2013;25(43):6284-90.

[16] Liu X, Antonietti M. Molten salt activation for synthesis of porous carbon nanostructures and carbon sheets. Carbon 2014;69:460-6.

[17] Liu X, Fechler N, Antonietti M, Willinger MG, Schlogl R. Synthesis of novel 2d carbon materials: sp2 carbon nanoribbon packing to form well-defined nanosheets. Mater Horizons 2016;3(3):214-9.

[18] Pampel J, Denton C, Fellinger T-P. Glucose derived ionothermal carbons with tailor-made porosity. Carbon 2016;107:288-96.

[19] Pampel J, Fellinger TP. Opening of Bottleneck Pores for the Improvement of Nitrogen Doped Carbon Electrocatalysts. Adv Energy Mater 2016;6(8):8.

[20] Pampel J, Mehmood A, Antonietti M, Fellinger TP. Ionothermal template transformations for preparation of tubular porous nitrogen doped carbons. Mater Horizons 2017;4(3):493-501. 
[21] Fechler N, Fellinger T-P, Antonietti M. "Salt Templating": A Simple and Sustainable Pathway toward Highly Porous Functional Carbons from Ionic Liquids. Adv Mater 2013;25(1):75-9.

[22] Fechler N, Wohlgemuth S-A, Jaker P, Antonietti M. Salt and sugar: direct synthesis of high surface area carbon materials at low temperatures via hydrothermal carbonization of glucose under hypersaline conditions. J Mater Chem A 2013;1(33):9418-21.

[23] Elumeeva K, Fechler N, Fellinger TP, Antonietti M. Metal-free ionic liquidderived electrocatalyst for high-performance oxygen reduction in acidic and alkaline electrolytes. Mater Horizons 2014;1(6):588-94.

[24] Ma Z, Zhang H, Yang Z, Zhang Y, Yu B, Liu Z. Highly mesoporous carbons derived from biomass feedstocks templated with eutectic salt $\mathrm{ZnCl} / \mathrm{KCl}$. J Mater Chem A 2014;2(45):19324-9.

[25] He C, Wu S, Zhao N, Shi C, Liu E, Li J. Carbon-Encapsulated Fe3O4 Nanoparticles as a High-Rate Lithium Ion Battery Anode Material. ACS Nano 2013;7(5):4459-69.

[26] Zhu S, Li J, He C, Zhao N, Liu E, Shi C, et al. Soluble salt self-assemblyassisted synthesis of three-dimensional hierarchical porous carbon networks for supercapacitors. J Mater Chem A 2015;3(44):22266-73.

[27] Chen L, Wang Z, He C, Zhao N, Shi C, Liu E, et al. Porous Graphitic Carbon Nanosheets as a High-Rate Anode Material for Lithium-Ion Batteries. ACS App Mater Interfases 2013;5(19):9537-45.

[28] Deng J, Xiong T, Xu F, Li M, Han C, Gong Y, et al. Inspired by bread leavening: one-pot synthesis of hierarchically porous carbon for supercapacitors. Green Chem 2015;17(7):4053-60.

[29] Sevilla M, Fuertes AB. A Green Approach to High-Performance Supercapacitor Electrodes: The Chemical Activation of Hydrochar with Potassium Bicarbonate.

ChemSusChem 2016;9(14):1880-8.

[30] Sevilla M, Ferrero GA, Fuertes AB. Beyond $\mathrm{KOH}$ activation for the synthesis of superactivated carbons from hydrochar. Carbon 2017;114:50-8.

[31] Schneidermann C, Jäckel N, Oswald S, Giebeler L, Presser V, Borchardt L. Solvent-Free Mechanochemical Synthesis of Nitrogen-Doped Nanoporous Carbon for Electrochemical Energy Storage. ChemSusChem 2017;10(11):2416-24.

[32] Sevilla M, Fuertes AB. A general and facile synthesis strategy towards highly porous carbons: carbonization of organic salts. J Mater Chem A 2013;1(44):13738-41.

[33] Ferrero GA, Sevilla M, Fuertes AB. Mesoporous carbons synthesized by direct carbonization of citrate salts for use as high-performance capacitors. Carbon 2015;88:239-51.

[34] Fuertes AB, Sevilla M. Hierarchical Microporous/Mesoporous Carbon Nanosheets for High-Performance Supercapacitors. ACS App Mater Interfases 2015;7(7):4344-53.

[35] Sevilla M, Fuertes AB. Direct Synthesis of Highly Porous Interconnected Carbon Nanosheets and Their Application as High-Performance Supercapacitors. ACS Nano 2014;8(5):5069-78.

[36] ISO 9277:2010. Determination of the specific surface area of solids by gas adsorption - BET method. Second Edition of ISO 9277, ISO. Geneva; 2012.

[37] Stoller MD, Ruoff RS. Best practice methods for determining an electrode material's performance for ultracapacitors. Energy Environ Sci 2010;3(9):1294-301. [38] Tuinstra F, Koenig JL. Raman Spectrum of Graphite. The Journal of Chemical Physics 1970;53(3):1126-30. 
[39] Ferrari AC. Raman spectroscopy of graphene and graphite: Disorder, electronphonon coupling, doping and nonadiabatic effects. Solid State Commun 2007;143(12):47-57.

[40] Liu Q, Duan Y, Zhao Q, Pan F, Zhang B, Zhang J. Direct Synthesis of NitrogenDoped Carbon Nanosheets with High Surface Area and Excellent Oxygen Reduction Performance. Langmuir 2014;30(27):8238-45.

[41] Pels JR, Kapteijn F, Moulijn JA, Zhu Q, Thomas KM. Evolution of nitrogen functionalities in carbonaceous materials during pyrolysis. Carbon 1995;33(11):164153.

[42] Schmiers H, Friebel J, Streubel P, Hesse R, Köpsel R. Change of chemical bonding of nitrogen of polymeric $\mathrm{N}$-heterocyclic compounds during pyrolysis. Carbon 1999;37(12):1965-78.

[43] Sevilla M, Sangchoom W, Balahmar N, Fuertes AB, Mokaya R. Highly Porous Renewable Carbons for Enhanced Storage of Energy-Related Gases (H2 and CO2) at High Pressures. ACS Sustain Chem Eng 2016;4(9):4710-6.

[44] Fuertes AB, Sevilla M. High-surface area carbons from renewable sources with a bimodal micro-mesoporosity for high-performance ionic liquid-based supercapacitors. Carbon 2015;94(0):41-52.

[45] Fuertes AB, Sevilla M. Superior Capacitive Performance of Hydrochar-Based Porous Carbons in Aqueous Electrolytes. ChemSusChem 2015;8(6):1049-57.

[46] Wei L, Sevilla M, Fuertes AB, Mokaya R, Yushin G. Polypyrrole-Derived Activated Carbons for High-Performance Electrical Double-Layer Capacitors with Ionic Liquid Electrolyte. Adv Funct Mater 2012;22(4):827-34.

[47] Sevilla M, Valle-Vigon P, Fuertes AB. N-Doped Polypyrrole-Based Porous Carbons for CO2 Capture. Adv Funct Mater 2011;21(14):2781-7.

[48] Lee D-W, Jin M-H, Oh D, Lee S-W, Park J-S. Straightforward Synthesis of Hierarchically Porous Nitrogen-Doped Carbon via Pyrolysis of Chitosan/Urea/KOH Mixtures and Its Application as a Support for Formic Acid Dehydrogenation Catalysts. ACS Sustain Chem Eng 2017;5(11):9935-44.

[49] Tsubouchi N, Nishio M, Mochizuki Y. Role of nitrogen in pore development in activated carbon prepared by potassium carbonate activation of lignin. Applied Surface Science 2016;371(Supplement C):301-6.

[50] McKee DW. Fundamentals of Catalytic Coal and Carbon GasificationMechanisms of the alkali metal catalysed gasification of carbon. Fuel 1983;62(2):170-5.

[51] Hayashi Ji, Horikawa T, Takeda I, Muroyama K, Nasir Ani F. Preparing activated carbon from various nutshells by chemical activation with K2CO3. Carbon 2002;40(13):2381-6. 